\title{
Telithromycin: The Perils of Hasty Adoption and Persistence of Off-Label Prescribing
}

\author{
Patrick P. Gleason, PharmD, BCPS, FCCP; Carol Walters, MBA; \\ Alan H. Heaton, PharmD; and Jeremy A. Schafer, PharmD
}

\begin{abstract}
BACKGROUND: Telithromycin (Ketek) was approved in April 2004 for the treatment of acute bacterial exacerbations of chronic bronchitis (ABECB), bacterial sinusitis, and community-acquired pneumonia. The approval of telithromycin was controversial due to trial irregularities, noninferiority study designs, and use of foreign safety data. Safety concerns involving hepatotoxicity, myasthenia gravis exacerbation, and visual disturbances were increasingly documented in the literature after approval. On February 12, 2007, the U.S. Food and Drug Administration (FDA) removed the bacterial sinusitis and ABECB indications and strengthened safety warnings for telithromycin.

OBJECTIVE: To (1) assess the prevalence and distribution of on-label telithromycin utilization before and after the revisions of the product label and (2) assess the association of pivotal events in the life cycle of telithromycin with its use as reflected in pharmacy and medical claims.

METHODS: Using retrospective administrative medical and pharmacy claims from a large midwestern commercial insurer with an eligible membership of 1.8 million members, individuals with a telithromycin claim during January 1 , 2007, through April 13, 2007, were identified. Their medical claims within 30 days prior to or on the initial telithromycin claim were analyzed for the presence of an on-label diagnosis code. Monthly telithromycin and clarithromycin claim totals per million members from January 2004 through March 2007 were calculated. Claim totals were plotted to identify utilization trends in relation to the FDA health advisory for telithromycin on January 20, 2006, and the telithromycin label changes on February 12, 2007.
\end{abstract}

RESULTS: The medical diagnosis analysis consisted of 507 members with 1 or more medical claims with dates of service within 30 days of at least 1 pharmacy claim for telithromycin. Using the original approved telithromycin indications, $52.3 \%$ ( 256 of 507 ) of telithromycin use was on-label. The most common on-label diagnoses were sinusitis $(33.9 \%)$ and bronchitis (14.4\%). A diagnosis of pneumonia was present for $3.9 \%$ of telithromycin utilizers. After the February 12,2007 , label change limiting telithromycin to community-acquired pneumonia, on-label use was $6.7 \%$ (12 of 179) of utilizers. Telithromycin claims were first detected in August 2004 and overtook the clarithromycin rate of 729 claims per million members in January 2005, reaching a peak rate of 940 claims per million members in January 2006. Telithromycin monthly claims remained higher than clarithromycin until April 2006, 3 months after the liver toxicity health advisory. In comparison with January 2006, the January 2007 telithromycin claims were 186 claims per million members, a decrease of $80 \%$.

CONCLUSION: Despite revised FDA indications and safety warnings, fewer than 1 in 15 active telithromycin users have a medical claim consistent with the only currently approved indication (pneumonia). Pharmacy claims for telithromycin dropped substantially following reports of severe hepatotoxicity and strengthened safety warnings. The high prevalence of telithromycin off-label use despite hepatotoxicity and other safety risks is cause for continued concern.

KEYWORDS: Telithromycin, Utilization, Administrative claims, Diagnoses

J Manag Care Pharm. 2007;13(5):420-25

Copyright@ 2007, Academy of Managed Care Pharmacy. All rights reserved.

Note: An editorial on the subject of this article appears on pages 429-30 of this issue.

\section{What is already known about this subject}

- Telithromycin-the first ketolide antibiotic-has been linked to dozens of cases of severe liver injury after its use for various respiratory infections.

- The U.S. Food and Drug Administration has withdrawn 2 indications due to safety concerns, leaving community-acquired pneumonia as the only remaining indication for telithromycin use, with a black-box warning.

\section{What this study adds}

- After overtaking clarithromycin use during the first year of product launch, telithromycin claims declined significantly, likely in response to safety concerns.

- Although pharmacy claims dropped after addition of the blackbox warning, telithromycin off-label use is still rampant $(93.3 \%$ of all users).

- This knowledge should spur health plans and pharmacy benefit managers to be more diligent in assessing drug use according to approved indications and, in the future, promote slower adoption of new drug products in the marketplace.

$\mathrm{T}$ elithromycin (Ketek) was approved on April 1, 2004, for the treatment of acute bacterial exacerbations of chronic bronchitis (ABECB), bacterial sinusitis, and communityacquired pneumonia (CAP). ${ }^{1}$ Telithromycin is similar in structure and mechanism of action to macrolides (e.g., clarithromycin). Telithromycin was the first of the ketolide class of antimicrobials approved by the U.S. Food and Drug Administration (FDA) with a mechanism of action inhibiting protein synthesis by binding to domains II and V of the $50 \mathrm{~S}$ ribosome. ${ }^{2}$ This dual mechanism of action allows telithromycin to retain activity against macrolideresistant organisms. This is perceived to be important since penicillin and macrolide nonsusceptible Streptococcus pneumoniae strains continue to increase in prevalence according to in vitro studies. ${ }^{3,4}$ However, the clinical importance of antimicrobial treatment for sinusitis and ABECB is unclear. ${ }^{5}$ Due to the unique mechanism of action and spectrum of activity, telithromycin was seen as a potentially valuable outpatient therapy for upper respiratory tract infections (e.g., sinusitis), $\mathrm{ABECB}$, and CAP.

The approval process of telithromycin was controversial. The initial application for approval was rejected by the FDA in June 2001, citing a need for additional safety data. ${ }^{6}$ Study 3014 was a randomized controlled trial designed to address safety concerns; it 
involved more than 24,000 patients. 6,7 Although study 3014 was completed in 5 months and found that telithromycin was comparable to amoxicillin/clavulanate in terms of safety, a routine FDA inspection uncovered fraud, including fabrication of data and violation of conduct; 4 of the top 10 patient-recruiting sites were referred for criminal investigation. ${ }^{7}$ In response to the irregularities of study 3014, the FDA deviated from usual policy and proposed analysis of unreliable foreign postmarketing reports to confirm telithromycin's safety. ${ }^{7}$

In addition to recruiting violations and use of rarely approved safety data, clinical trials studying telithromycin for $\mathrm{ABECB}$ and bacterial sinusitis used methodology no longer accepted by the FDA; they were powered for noninferiority, which is no longer recommended. ${ }^{7}$ Noninferiority trials are designed to simply identify if a therapy is less effective than the comparator by a predefined maximal margin, and still better than placebo. In 2004, the foreign safety reports combined with specious clinical trial data led to the approval of telithromycin. ${ }^{6,7}$

Severe adverse events associated with telithromycin use arose shortly after approval. A report published in the Annals of Internal Medicine described 3 cases of severe hepatotoxicity in patients treated with telithromycin. ${ }^{8}$ Outcomes for the 3 patients varied in severity with one patient recovering upon discontinuation of telithromycin, a second patient requiring liver transplantation, and the third dying of acute liver failure. ${ }^{8}$ An analysis of the FDA's postmarketing database revealed a 3.5 to 11 times higher incidence of acute liver failure associated with telithromycin compared with other antimicrobials. ${ }^{9}$ A reported rate of 167 cases of acute liver failure per 1 million person-years of telithromycin use has been documented. ${ }^{9}$

Additional safety concerns associated with telithromycin use appeared in the literature, including exacerbation or unmasking of myasthenia gravis. ${ }^{10,11}$ Cases occurred shortly after telithromycin administration and would often resolve upon discontinuation of the drug. ${ }^{10}$ Visual adverse events including blurred vision, difficulty focusing, and diplopia occur in $0.27 \%$ to $2.1 \%$ of patients treated with telithromycin. ${ }^{12}$ Telithromycin is also a potent inhibitor of CYP3A4, increasing the risk for serious drug-drug interactions. ${ }^{12}$

In response to mounting safety concerns, on February 12, 2007, the FDA issued revised labeling and updated safety information for telithromycin. ${ }^{13}$ Indications for $\mathrm{ABECB}$ and bacterial sinusitis were removed. A black-box warning contraindicating the use of telithromycin in patients with myasthenia gravis was added. Finally, warnings regarding liver toxicity, visual disturbances, and loss of consciousness were strengthened.

Telithromycin presents a unique challenge for managed care. Notification of labeling changes can be slow to reach many providers. As a result, members may continue to be prescribed telithromycin for indications where the benefits are no longer outweighed by the risks. Analysis of pharmacy claims in relation to major events in a drug's life cycle may provide insight as to how effectively information is disseminated and the degree of impact this information has on prescribing practices.

The objective of this study was to assess the prevalence of onlabel telithromycin utilization before and after the revisions of the product label and assess how the occurrence of pivotal events in the medication's life cycle are reflected in pharmacy claims.

\section{Methods}

Using retrospective administrative medical and pharmacy claims from a large midwestern commercial insurer with 1.8 million eligible members, individuals with a telithromycin date of service claim during January 1, 2007, through April 13, 2007, were identified using SAS software (SAS Institute Inc., Cary, NC). Medical data on members with a claim for telithromycin with a date of service during the period from January 1, 2007, through April 13, 2007, were retrieved and integrated. An integrated medical and pharmacy claims dataset containing all medical claims for members with telithromycin claims with dates of service from January 1, 2007, through April 13, 2007, was created. A subdataset containing only members with telithromycin claims with dates of service during the 60 days after the telithromycin label change (February 13, 2007, through April 13, 2007) was created.

Medical claims were searched for a diagnosis of pneumonia (International Classification of Diseases, Ninth Revision, Clinical Modification [ICD-9-CM] codes 480.xx through 486.xx), bronchitis (ICD-9-CM codes 466.xx), sinusitis (ICD-9-CM code 461.xx), upper respiratory tract infection (URI, ICD-9-CM codes 460.xx, 462.xx through 465.xx, 032.xx through 034.xx), influenza (ICD-9-CM codes 487.xx), asthma ICD-9-CM codes 493.xx), chronic obstructive pulmonary disease (COPD, ICD-9-CM codes 490.xx through 492.xx or 494.xx or 496.xx), or cough (ICD-9-CM 786.0x through 786.49) within 30 days prior to or on the date of the initial telithromycin claim in all available fields. Members with multiple diagnoses were classified by highest diagnosis on a hierarchical scale. Ranking of diagnosis from highest to lowest were as follows: pneumonia, bronchitis, sinusitis, URI, influenza, asthma, COPD, and cough. For example, a patient with medical diagnoses of pneumonia and cough would be classified as a pneumonia patient. Patients with a medical claim for a diagnosis not listed above were categorized as unspecified.

Pharmacy claims data were analyzed for frequency of occurrence and percent of patients with each corresponding diagnosis on the medical claims. A second analysis of the impact of major events on telithromycin utilization was also conducted. Telithromycin claims per million members from date of approval (April 2004) to present (March 2007) were totaled on a per-month basis. Two major events were identified: the FDA public health advisory and publication of the Annals of Internal Medicine case reports of severe hepatotoxicity (January 2006) and the revision of product labeling by the FDA (February 2007).8,13,14 Clarithromycin tablet (extended release and immediate formulations) claims for the same period were included as a reference comparison using the same methodology. Clarithromycin suspension was not included in this analysis 


\begin{tabular}{|c|c|c|c|}
\hline Diagnosis & $\mathrm{N}=507^{*}$ & $\%$ & $\begin{array}{c}\text { FDA-Approved } \\
\text { Indications Prior to } \\
\text { February } 12,2007\end{array}$ \\
\hline Pneumonia & 20 & 3.9 & Yes \\
\hline Bronchitis & 73 & 14.4 & Yes \\
\hline Sinusitis & 172 & 33.9 & Yes \\
\hline $\begin{array}{l}\text { Upper respiratory } \\
\text { infection (excluding } \\
\text { sinusitis) }\end{array}$ & 75 & 14.8 & No \\
\hline Asthma & 15 & 3.0 & No \\
\hline COPD & 30 & 5.9 & No \\
\hline Cough & 7 & 1.4 & No \\
\hline $\begin{array}{l}\text { Medical claim with } \\
\text { none of the above } \\
\text { diagnoses }\end{array}$ & 115 & 22.7 & No \\
\hline \multicolumn{4}{|c|}{$\begin{array}{l}\text { * There were } 649 \text { claims for telithromycin filled for } 587 \text { members during the period } \\
\text { from January 1,2007, through April 13, 2007; } 80 \text { of the } 587 \text { (13.6\%) members } \\
\text { had no medical claims with a date of service within } 30 \text { days of the initial telithro- } \\
\text { mycin claim. } \\
\text { COPD =chronic obstructive pulmonary disease; FDA =U.S. Food and Drug } \\
\text { Administration. }\end{array}$} \\
\hline
\end{tabular}

\begin{tabular}{|c|c|c|c|}
\hline TABLE 2 ) & $\begin{array}{l}\text { edical D } \\
\text { sers Afte } \\
\text { ebruary }\end{array}$ & $\begin{array}{l}\text { רoses } \\
\text { PA La } \\
2007\end{array}$ & $\begin{array}{l}\text { ithromycin } \\
\text { vision on }\end{array}$ \\
\hline Diagnosis & $\mathrm{N}=179 \dagger$ & $\% \neq$ & $\begin{array}{c}\text { FDA-Approved } \\
\text { Indications on } \\
\text { February } 12,2007\end{array}$ \\
\hline Pneumonia & 12 & 6.7 & Yes \\
\hline Bronchitis & 23 & 12.8 & No \\
\hline Sinusitis & 61 & 34.1 & No \\
\hline $\begin{array}{l}\text { Upper respiratory } \\
\text { infection (excluding } \\
\text { sinusitis) }\end{array}$ & 14 & 7.8 & No \\
\hline Asthma & 12 & 6.7 & No \\
\hline$\overline{\text { COPD }}$ & 7 & 3.9 & No \\
\hline$\overline{\text { Cough }}$ & 4 & 2.2 & No \\
\hline $\begin{array}{l}\text { Medical claim with } \\
\text { none of the above } \\
\text { diagnoses }\end{array}$ & 46 & 25.7 & No \\
\hline $\begin{array}{l}\text { * The telithromycin la } \\
1 \text { approved indicatio } \\
+210 \text { members had a } \\
2007 ; 31 \text { of the } 210 \\
\text { service within } 30 \text { da } \\
\text { † Percentages add up } \\
\text { COPD = chronic obstru } \\
\text { Administration. }\end{array}$ & $\begin{array}{l}\text { was change } \\
\text { for the treat } \\
\text { thromycin c } \\
4.8 \% \text { memb } \\
\text { f the initial } \\
9.9 \% \text { due to } \\
\text { e pulmonar }\end{array}$ & $\begin{array}{l}\text { he FDA } \\
\text { f pneun } \\
\text { etween } \\
\text { d no me } \\
\text { omycin } \\
\text { ling. } \\
\text { ase; } F D\end{array}$ & $\begin{array}{l}\text { ary } 12,2007 \text {, to only } \\
\text { 13, 2007, and April } 13 \\
\text { ms with a date of } \\
\text { Food and Drug }\end{array}$ \\
\hline
\end{tabular}

because a suspension formulation of telithromycin is not available.

A limited data set was obtained after direct individual identifiers were removed to meet the requirements of HIPAA (Health Insurance Portability and Accountability Act). Consistent with the National Bioethics Advisory Commission exemption of activities considered research, the purpose of these analyses were not intended to generate scientific knowledge but, rather, to improve pharmacy benefit management of drugs with new safety concerns. ${ }^{15}$

\section{Results}

During the period of January 1, 2007, to April 13, 2007, 649 claims for telithromycin were filled for 587 members. For 80 of the 587 (13.6\%) members, no medical claims were filed within 30 days of their initial telithromycin claim. This left, for our analysis, 507 members with a medical claim indicating the member was seen by a provider within 30 days of the telithromycin pharmacy claim. A medical claim within 7 days of the telithromycin claim was present in $90.3 \%$ (458 of 507) members. Using the original FDAapproved telithromycin indications to define an on-label diagnosis, an on-label diagnosis was present for 52.3\% (265 of 507) of telithromycin utilizers (Table 1). The most common medical diagnosis was sinusitis, which occurred in 172 (33.9\%) members, followed by a medical claim lacking a defined ICD9-CM for this study (i.e., pneumonia, bronchitis, sinusitis, URI, influenza, asthma, COPD, or cough) (115 of 507, 22.7\%). A medical diagnosis of pneumonia was present for 20 (3.9\%) members. Members with a medical claim who filled a telithromycin prescription after the change in telithromycin-approved indications to only pneumonia on February 12, 2007, were analyzed (Table 2). One hundred seventy-nine members were available for this analysis. An on-label diagnosis of pneumonia was present in 12 (6.7\%) members. The majority of these members (61 of $179,34.1 \%$ ) had a sinusitis medical diagnosis.

Claims for telithromycin increased rapidly after the product's launch, surpassing clarithromycin tablets in January 2005 and reaching a peak of 975 claims per million members in March 2005 and outpaced clarithromycin claims of 757 per million members for the month (see Figure). Telithromycin and clarithromycin claims declined steadily as the spring/summer months began, reaching lows of 337 and 294 per million members, respectively, in July 2005. The beginning of the fall months and progression into the winter of 2006 again saw a rapid rise in claims for both agents. Peaks of 940 telithromycin and 625 clarithromycin claims per million members were submitted in January 2006 and December 2005, respectively. On January 20, 2006, the Annals of Internal Medicine case reports and FDA health advisory of severe hepatotoxicity were published. .13 $^{8}$ The usual seasonal decline in both telithromycin and clarithromycin claims were already occurring at this point. Clarithromycin claims rose again in the fall of 2006 and continued into the winter of 2007 , peaking at 643 per million members in January 2007. Telithromycin claims saw only a modest 


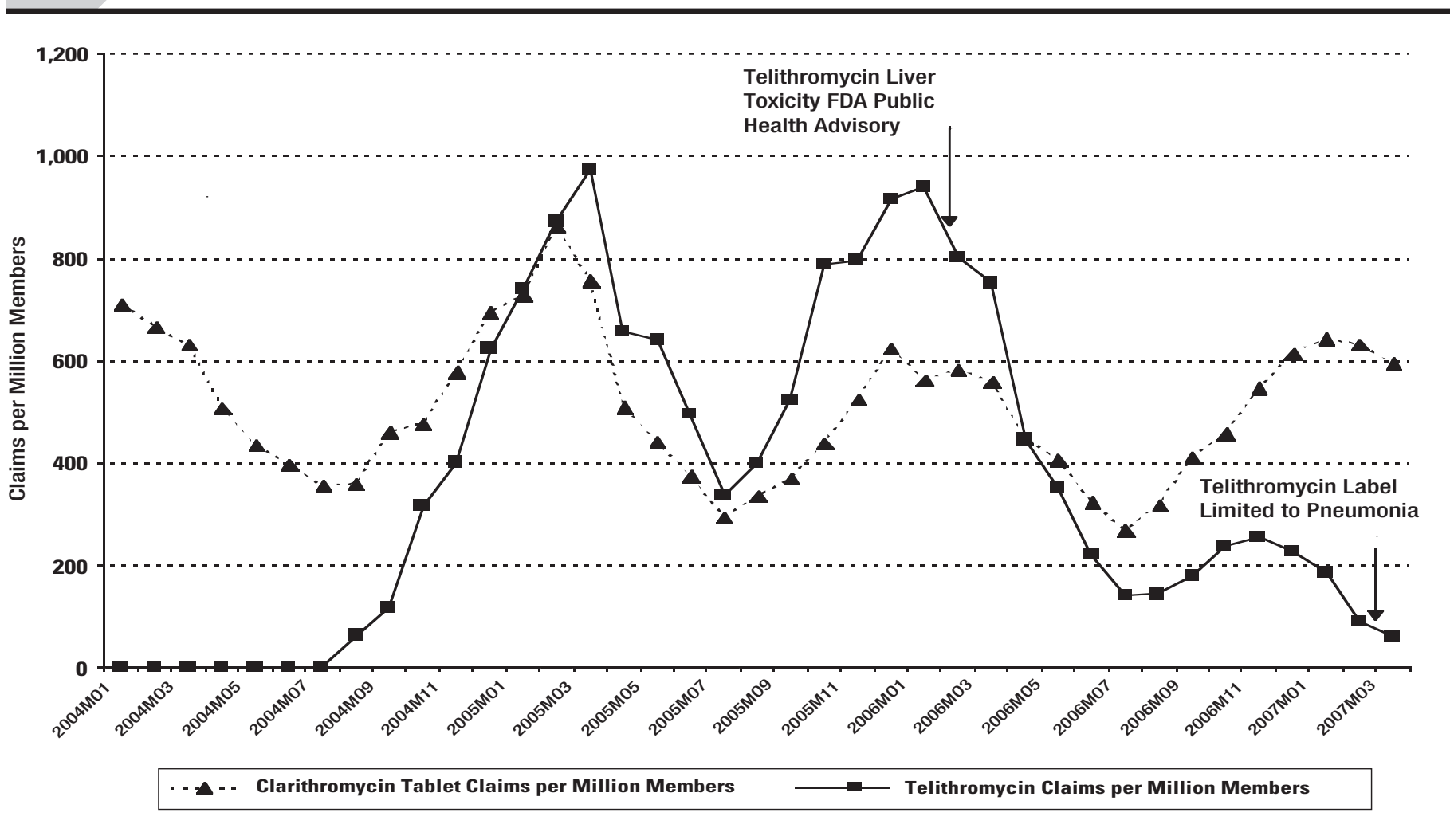

FDA $=$ U.S. Food and Drug Administration.

increase with a peak of 254 claims per million members in November 2006. On February 12, 2007, the FDA issued revised labeling for telithromycin. Telithromycin claims declined steadily, reaching a low of 61 claims per million members for the month of March compared with 595 for clarithromycin.

\section{Discussion}

Telithromcyin's unique mechanism of action, ease of use, and activity against macrolide resistant organisms made this agent an attractive new option for treatment of community-acquired infections. However, safety concerns of liver toxicity, visual disturbances, and myasthenia gravis exacerbations overshadowed the potential benefits. We conducted a retrospective analysis of claims data for telithromycin with emphasis on 2 events: the publication of cases of severe hepatotoxicity and the revised FDA labeling.

Our analysis identified inappropriate telithromycin use before and after the FDA intervention. Sinusitis was the diagnosis in $33.9 \%$ of patients overall and $34.1 \%$ of members after February 12, 2007. This implies steady telithromycin utilization for indications that the risks of therapy are now deemed greater than the potential benefits. Pneumonia was the diagnosis in 3.9\% of patients. After the FDA action, pneumonia was the diagnosis in only $6.7 \%$ of patients despite pneumonia being the only approved indication. Unfortunately, inappropriate antimicrobial use in managed care systems is common. A study by Stallworth et al. found that children with asthma were more likely to receive antimicrobials for illnesses likely caused by viruses such as bronchitis than nonasthmatic children (odds ratio, 3.3, 95\% confidence interval, 2.97-3.66). ${ }^{16}$

Publication of serious adverse events or safety interventions by the FDA often has a negative effect on number of claims. In our analysis, claims for telithromycin dropped 80\% from January 2006 to January 2007 after the publication of case reports regarding severe hepatotoxicity. Although part of this decline could be explained by seasonal changes, the rebound of telithromycin claims in the winter of 2006-2007 was low in comparison with the winters of 2004-2005 and 2005-2006. Telithromycin utilization reached an all-time low in March 2007 after the revised FDA warnings occurred in February 2007. Cyclooxygenase (COX)-2 inhibitors suffered a similar fate after the withdrawal of rofecoxib in September 
2004. Gunderson et al. reported that claims for COX-2 inhibitors (celecoxib, rofecoxib, valdecoxib) fell from 30 to 35 claims/10,000 members in September 2004 to less than 15 claims/10,000 members by February 2005. ${ }^{17}$

A study by Wilkinson et al. found that multiple safety warnings were necessary before use of cisapride and troglitazone declined. Overall use declined for cisapride after 5 alerts and after 4 alerts for troglitazone. ${ }^{18}$ Telithromycin appears to have declined rapidly after 2 safety warnings. In comparison with January 2006, the January 2007 telithromycin claims decreased by $80 \%$ and clarithromycin claims increased by $14 \%$. The apparent quick telithromycin decline may be due to telithromycin's short-term $(<14$ day therapy) episodic use as opposed to cisapride's and troglitazone's chronic use. Although telithromycin use was considerably lower than clarithromycin use in the winter months of 2006-2007, another winter season will be necessary to verify these findings.

The decline in telithromycin use is understandable as the riskto-benefit ratio has been found unacceptable for the treatment of sinusitis and $A B E C B$. Only for the more serious condition of pneumonia has telithromycin been found to have an acceptable risk to benefit ratio. Unfortunately, only 1 of 25 members treated with telithromycin had a documented diagnosis of pneumonia during early 2007.

Managed care organizations have several options to address concerns with telithromycin use. Provider education initiatives including retrospective drug utilization review (DUR) can increase prescriber awareness of new safety warnings. Kaufman et al. used a letter and telephone system to educate providers prescribing contraindicated medications to elderly patients. ${ }^{19}$ Incidence of inappropriate medication use declined 19\%. ${ }^{19}$ Significant reductions in the number of elderly persons who received contraindicated medications and persons receiving 1 or more of 7 contraindicated medications were also documented. ${ }^{19}$ We have already begun a retrospective DUR education program for our providers concerning telithromycin. Additional options for managed care organizations to consider would be prior authorization limiting the use of telithromycin to patients with pneumonia who have failed multiple first-line agents, and/or removal of the agent from the formulary.

\section{Limitations}

The study was intended to explore potential associations between the FDA safety warning and label change and telithromycin utilization; a direct cause-and-effect link cannot be made. Medical and pharmacy claims data are limited by the nature of the data. The administrative claims data are believed to be an accurate representation of the members' actual medical diagnoses, and we did not perform either chart review or have electronic medical records available to audit absent medical diagnosis information.

Our study assumes that coincident medical claims are linked to the telithromycin claim. The finding that 80 of 587 (13.6\%) members lacked a medical claim within 30 days of their initial telithromycin claim appears high, however, members could have interacted with their prescriber outside of the clinic setting (e.g., telephone) resulting in the telithromycin prescription being phoned in to the pharmacy. In addition, we used the date of service field on the pharmacy claim to identify the date the member filled the telithromycin prescription and the date of service field on the medical claim to signify the date the member was seen by the physician. Members may have been instructed to wait or may have on their own delayed filling their telithromycin prescription, in which case we would have misclassified the member as lacking a medical claim within 30 days of their initial telithromycin claim; e.g., a prescription written in mid-January 2007 but not filled until mid-March 2007. However, the majority of coincident medical claims were associated with an infectious illness, and we believe patients are likely to fill prescriptions for antimicrobial medications soon after receiving them. Our data are also limited to a specific geographical region in the Midwest and may not be generalized to Medicare or Medicaid populations or other geographic regions.

\section{Conclusion}

New safety concerns led to a more obvious negative risk-to-benefit ratio for telithromycin in the treatment of sinusitis and ABECB. Despite revised FDA indications, use of telithromycin for disease states not listed on the product label is still common. Fewer than 1 in 15 users of telthromycin had a pneumonia diagnosis, the only remaining approved indication. Utilization of telithromycin dropped substantially following reports of severe hepatotoxicity, strengthened safety warnings, and label changes. The high rate of off-label telithromycin use is cause for continued concern. Options available to managed care organizations include retrospective DUR provider education, prior-authorization programs, or formulary removal. Managed care professionals should be proactive in the education of patients and providers to reduce the risk of serious complications associated with telithromycin therapy.

\section{Authors}

PATRICK P. GLEASON, PharmD, BCPS, FCCP, is director, medical and pharmacy integration services; CAROL WALTERS, MBA, is a senior consultant analyst; and JEREMY A. SCHAFER, PharmD, is a senior clinical pharmacist, Prime Therapeutics LLC, Eagan, Minnesota; Gleason is also an adjunct clinical assistant professor, College of Pharmacy, University of Minnesota, Minneapolis. ALAN H. HEATON, PharmD, is director of pharmacy, BlueCross BlueShield of Minnesota, Eagan, and assistant professor, Graduate School of Public Health, University of Minnesota, Minneapolis.

AUTHOR CORRESPONDENCE: Patrick P. Gleason, PharmD, BCPS, FCCP, Prime Therapeutics LLC, 1305 Corporate Center Dr., Eagan, MN 55121. Tel: (651) 286-4190; Fax: (651) 286-4409;

E-mail:pgleason@primetherapeutics.com 


\section{ACKNOWLEDGMENT}

The authors thank Brent Gunderson, PharmD, senior clinical pharmacist, Prime Therapeutics, LLC, for his editorial assistance on an earlier version of this article.

\section{DISCLOSURES}

No outside funding supported this study. Authors Patrick P. Gleason, Carol Walters, and Jeremy A. Schafer disclose that they are employed by a pharmacy benefits manager; author Alan $\mathrm{H}$. Heaton discloses that he is employed by a health insurance provider. Schafer also discloses that he has received honoraria from Abbott Laboratories and Theravance during a fellowship in 2005. Gleason served as principal author of the study. Study concept and design were primarily contributed by Gleason, with input from Schafer. Data collection was the work of Walters; data interpretation was primarily the work of Gleason, with input from Schafer and Heaton. Writing of the manuscript was the work of Schafer and Gleason; its revision was the work of all authors.

\section{REFERENCES}

1. Department of Health and Human Services. Approval letter for Ketek (telithromycin). Available at: http://www.fda.gov/cder/foi/appletter/2004/ 211441 tr.pdf. Accessed April 26, 2007.

2. Department of Health and Human Services. Ketek product label. Available at: http://www.fda.gov/cder/foi/label/2007/021144s012lbl.pdf. Accessed April 26, 2007.

3. Johnson DM, Stilwell MG, Fritsche TR, Jones RN. Emergence of multidrug resistant Streptococcus pneumoniae: report from the SENTRY antimicrobial surveillance program (1999-2003). Diagn Microbiol Infect Dis. 2006;56:69-74.

4. Karlowsky JA, Thornsberry C, Jones ME, et al. Factors associated with relative rates of antimicrobial resistance among Streptococcus pneumoniae in the United States: results from the TRUST surveillance program (1998-2002). Clin Infect Dis. 2003;36(8):963-970

5. Hirschmann JV. Antibiotics for common respiratory tract infections in adults. Arch Intern Med. 2002;162:256-64

6. Barie PS. A fine pile of pate: the cautionary tale of telithromycin, hepatic failure, and study 3014. Surgical Infect. 2006;7(3):247-49.
7. Ross DB. The FDA and the case of Ketek. N Engl J Med. 2007;356(16):1601-76. 8. Clay KD, Hanson JS, Pope SD, Rissmiller RW, Purdum PP, Banks PM. Brief communication: severe hepatotoxicity of telithromycin: three case reports and literature review. Ann Intern Med. 2006;144:415-20.

9. Graham DJ. Telithromycin and acute liver failure. N Engl J Med. 2006; 355(21):2260-61

10. Perrot X, Bernard N, Vial C, et al. Myasthenia gravis exacerbation or unmasking associated with telithromycin treatment. Neurology. 2006;67:2256-58.

11. Jennett AM, Bali D, Jasti P, Shah B, Browning LA. Telithromycin and myasthenic crisis. Clin Infect Dis. 2006;43:1621-22.

12. Lonks JR, Goldmann DA. Telithromycin: a ketolide antibiotic for treatment of respiratory tract infections. Clin Infect Dis. 2005;40:1657-64.

13. Department of Health and Human Services. Telithromycin (marketed as Ketek) information. Available at: http://www.fda.gov/cder/drug/infopage/ telithromycin/default.htm. Accessed April 26, 2007.

14. Department of Health and Human Services. FDA Public Health Advisory: Ketek (telithromycin) tablets. Available at: http://www.fda.gov/cder/drug/ advisory/telithromycin.htm. Accessed April 26, 2007.

15. National Commission for the Projection of the Protection of Human Subjects of Biomedical and Behavioral Research. The Belmont Report: Ethical Principles and Guidelines for the Protection of Human Subjects of Research. Washington, DC: U.S. Government Printing Office; 1978.

16. Stallworth LE, Fick DM, Ownby DR, Waller JL. Antibiotic use in children who have asthma: results of retrospective database analysis. J Manag Care Pharm. 2005;11(8):657-62. Available at: http://www.amcp.org/data/jmcp/ Original\%20Research\%20657-662.pdf. Accessed April 26, 2007.

17. Gunderson BW, Gleason PP, Johnson SV, Heaton AH. Trends in utilization of alternative analgesics after rofecoxib withdrawal. Formulary. 2005;40:224-26.

18. Wilkinson JJ, Force RW, Cady PS. Impact of safety warnings on drug utilization: marketplace life span of cisapride and troglitazone. Pharmacotherapy. 2004;24(8):978-86

19. Kaufman MB, Brodin KA, Sarafian A. Effect of prescriber education on the use of medications contraindicated in older adults in a managed Medicare population. J Manag Care Pharm. 2005;11(3):211-19. Available at: http://www.amcp.org/data/jmcp/Research_211-219.pdf. Accessed April 26, 2007. 